\title{
Modelling of UV radiation variations at different time scales
}

\author{
J. L. Borkowski \\ Institute of Geophysics, Polish Academy of Sciences, Poland \\ Received: 4 January 2007 - Revised: 21 December 2007 - Accepted: 21 January 2008 - Published: 26 March 2008
}

\begin{abstract}
Solar UV radiation variability in the period 19762006 is discussed with respect to the relative changes in the solar global radiation, ozone content, and cloudiness. All the variables were decomposed into separate components, representing variations of different time scales, using wavelet multi-resolution decomposition. The response of the UV radiation to the changes in the solar global radiation, ozone content, and cloudiness depends on the time scale, therefore, it seems reasonable to model separately the relation between UV and explanatory variables at different time scales. The wavelet components of the UV series are modelled and summed to obtain the fit of observed series. The results show that the coarser time scale components can be modelled with greater accuracy than fine scale components and the fitted values calculated by this method are in better agreement with observed values than values calculated by the regression method, in which variables were not decomposed. The residual standard error in the case of modelling with the use of wavelets is reduced by $14 \%$ in comparison to the regression method without decomposition.
\end{abstract}

Keywords. Atmospheric composition and structure (Transmission and scattering of radiation)

\section{Introduction}

In the last decades there has been increasing interest and activity in the area of ultraviolet (UV) radiation research, evoked by stratospheric ozone depletion (Bais et al., 2007). The prolonged increase in the UV radiation reaching the ground, caused by ozone depletion, could have disastrous consequences for humans and the environment. In addition, adverse effects of the UV radiation can be accumulated (Slaper et al., 1996), and knowledge of the past variations

Correspondence to: J. L. Borkowski

(borek@igf.edu.pl) over different time scales and trends is therefore necessary to assess the public health risk. Recently, the measurements of the UV radiation became more intense, however, there are still only very few long data series available, which can be used for establishing UV climatology and trend estimation. To overcome this difficulty a number of methods of reconstruction of the past UV records have been used. They are based on radiative transfer model calculations, statistical modelling, and hybrid models, combining radiative transfer model calculations with empirical estimates of the influence of various factors on UV radiation. Among them clouds introduce the greatest uncertainty in the evaluation of UV radiation reaching the ground (Calbó et al., 2005).

A comparison of different models, mainly based on a radiative transfer calculation, was made by Koepke et al. (1998) and Van Weele et al. (2000). Reconstruction models with the use of the Multivariate Adaptive Regression Splines (MARS) methodology, and a hybrid model was used by Krzyscin (2003) and Krzyscin et al. (2004). Lindfors et al. (2003), and Lindfors and Vuilleumier (2005) simulated daily clear sky UV doses using a radiative transfer model and a relation between the simulated clear sky dose, measured dose, sunshine duration and snow depth. Similarly, den Outer et al. (2005) obtained daily doses of UV radiation using the Tropospheric Ultraviolet-Visible (TUV) radiation transfer model for clear sky irradiances developed by Madronich (1993), and an empirical relationship between the clear sky UV daily dose and the cloud reduced dose. The intercomparison of the UV daily doses calculated with the use of 16 different models and comparison with measured values was made by Koepke et al. (2006).

In this work a purely statistical approach is applied in order to establish a relationship between UV radiation and ozone content, cloudiness and global solar radiation. These variables are usually used as explanatory variables in empirical models of UV radiation. The response of the UV radiation to the changes in these variables depends on the time scale

Published by Copernicus Publications on behalf of the European Geosciences Union. 
at which the response is considered. The short-term variations of the UV radiation at the surface are better correlated with changes in cloudiness while the longer scale UV variations can be attributed to ozone variations (Borkowski, 2002), therefore, it seems reasonable to model separately the relation between UV and explanatory variables at different time scales. To separate the components of the different time scales a wavelet multi-resolution decomposition is used.

\section{Data}

In the present study the results of the UV radiation, global solar radiation and total ozone measurements conducted at Belsk Observatory $\left(52^{\circ} 50^{\prime} \mathrm{N}, 20^{\circ} 47^{\prime} \mathrm{E}\right)$ in the period January 1976-July 2006 are used. Daily measurements of UV radiation with the use of a Robertson-Berger meter started in May 1975, and since 1993 a new UV-Biometer Mod 501A has been used. Despite some uncertainties connected with these instruments, if properly maintained and calibrated, they can be used not only for climatological purposes but also for trend detection of the erythemal UV-B doses (WMO, 1996; Seckmeyer et al., 2005). The Belsk UV meter is checked by comparison with model calculations and erythemally weighted measurements taken by a Brewer spectrophotometer. The Brewer instrument is regularly calibrated against Brewer\#17, maintained by the International Ozone Services. The Belsk UV-B data have been temperature corrected and homogenized (Borkowski, 2000) and were submitted to the European UV database. Measurements of the solar global radiation have been carried out by means of a Kipp\&Zonen CM11 pyranometer.

The total ozone measurements have been taken by means of the Dobson spectrophotometer No. 84. The monthly mean values used in this study are calculated on the basis of the daily values of the total ozone obtained according to WMO recommendations. The Belsk ozone data were reevaluated on a reading-by-reading basis, taking into account the calibration history of the instrument (WMO, 1990). Ozone data taken at Belsk were also several times compared with the data from external sources. Belsk's Dobson instrument has been compared with the European substandard, the Dobson No. 64 traceable to the World Standard Instrument, Dobson No. 83. Belsk ozone data were also compared with the results of satellite observations by TOMS (Total Ozone Mapping Spectrometer) and OMI (Ozone Monitoring Instrument) (Krzyscin et al., 2005; Rajewska-Wiech et al., 2006), and are sent to the World Ozone and Ultraviolet Radiation Data Center (WOUDC) at Toronto, Canada, and to the WMO Northern Hemisphere Daily Ozone Mapping Centre operated by the Laboratory of Atmospheric Physics at the Aristotle University of Thessaloniki (Greece).

The clouds data sets were taken from the database of the National Centers for Environmental Prediction NCEP (Reanalysis-2) Monthly Means and Anomalies. The monthly mean values of the total cloudiness and sky cover by low, middle and high clouds are used.

For UV-B daily doses, global solar radiation and total ozone amount, monthly mean values were calculated. For all variables fractional deviations of monthly averages from the long-term monthly mean value are used as basic data for further analysis. The use of such fractional deviations removes the dominant seasonal variations, which can obscure the important features of the data series.

\section{Multi-resolution decomposition of the data series us- ing wavelets}

Similar to the Fourier transform, in which a function is expanded in terms of the sine and cosine functions, the discrete wavelet transform uses the basis functions, which are constructed by dilatations and translations of the functions called the mother and father wavelets. The details of the wavelet techniques can be found elsewhere (e.g. Bruce and Gao, 1996).

The wavelet transform of a time series $f(t)$ enables us to perform a multi-resolution decomposition, which separates the series into components:

$f(t)=\sum_{j=1}^{J} D_{j}(t)+S_{J}(t)$,

where functions $S_{J}(t)$ and $D j(t)$ are called the smooth and detail components, respectively, and represent variations in $f(t)$ at a certain time scale. $J$ denotes the maximal level of the decomposition, and $J$ must be a number such that $2^{J} \leq n$, where $n$ is the number of observations. An advantage of the wavelet decomposition is that each component represents variations over a definite time scale, and it can be applied to a nonstationary time series. If $f(t)$ is a monthly time series of fractional deviations, as in our case, the $D_{j}$ component reflects changes over time scales from $2^{j-1}$ to $2^{j}$ months, and $S_{J}(t)$ is the smoothed version of $f(t)$ and reflects variations over a scale of $2^{J}$ months. In our analysis the nondecimated discrete wavelet transform (also known as maximal overlap discrete wavelet transform) are used. The non decimated transform is a variant of the classical discrete wavelet transform which provides increased resolution at coarser time scales and is translation-invariant. As a boundary treatment rule the reflection rule is applied because it minimizes artifacts at the boundaries. The waveslim software package for the analysis of a time series by Whitcher (2004) was used to perform a multi-resolution decomposition.

The idea of a multi-resolution decomposition is illustrated in Fig. 1, which shows components of the UV and ozone series with $J=7$. The smooth $\mathrm{S} 7$ component corresponds to low frequency oscillations with the time scale of about $2^{7}$ month $\approx 10$ years. The number of observations (367) allows for calculation of 8 levels, but the choice of 7 levels makes 

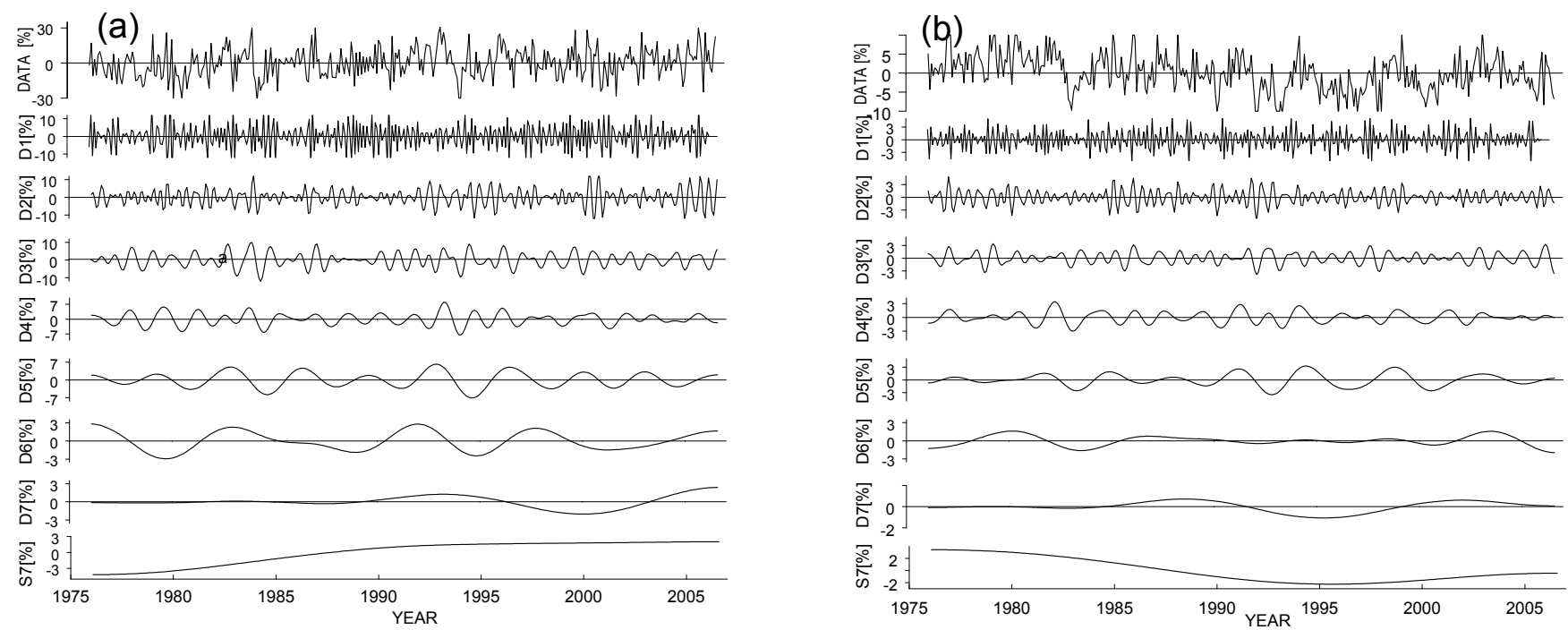

Fig. 1. Multi-resolution decomposition of the UV (a) and ozone (b) series.

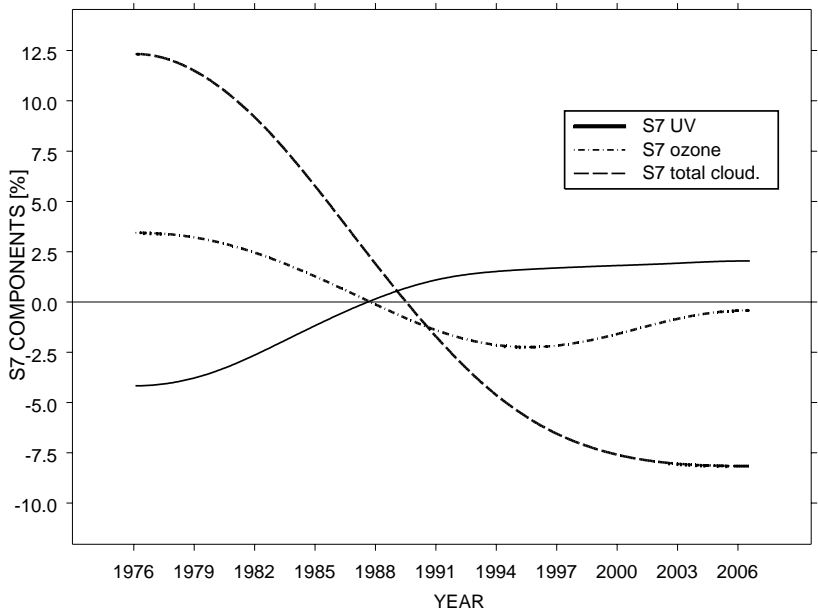

Fig. 2. Smooth (S7) components of the UV, ozone and cloudiness series.

it possible to capture the change in the rate of increase in the smooth component, while effectively eliminating the oscillation of a shorter time scale. The different response of $\mathrm{UV}$ to the changes in ozone at different time scales is clearly visible. The smooth component of the UV series looks almost like a symmetrical reflection of the same component of the ozone series. This is better seen in Fig. 2 where only the smooth components of the UV, ozone, and cloudiness are shown. The mean of the absolute value of the ratio of the S7 UV component to the S7 ozone component is 1.07. The value of the radiation amplification factor for the standard erythemal action spectrum (CIE, 1987) is close to 1.1 (Madronich et al., 1998), indicating that a 1\% decrease in total column ozone leads to a $1.1 \%$ increase in UV radiation,
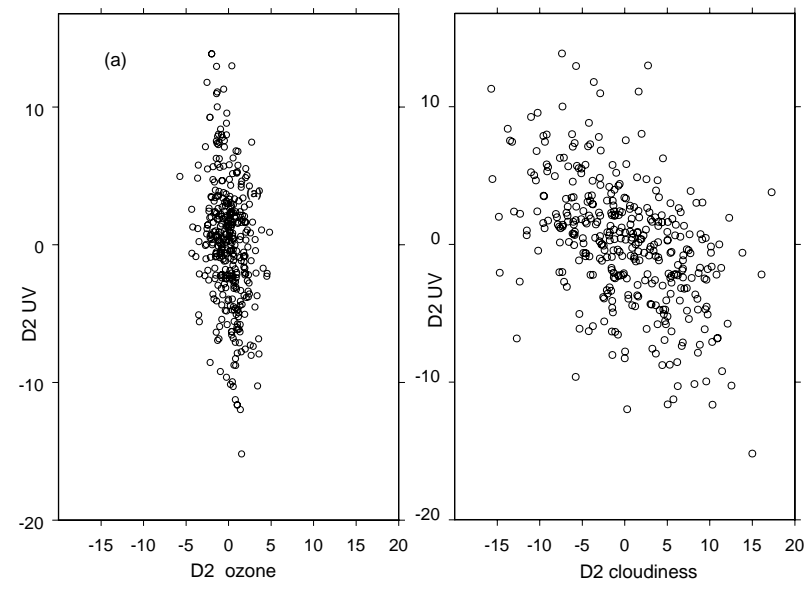

Fig. 3. D2 components of the UV ozone series as a function of the same components of the ozone (a), and cloudiness (b) series.

if other variables influencing UV radiation are kept constant. Thus, ozone changes can be recognised as a main cause of $\mathrm{UV}$ radiation at the longest time scale. However, we cannot completely exclude cloudiness as a factor influencing UV at this time scale. At the beginning of the observation period there is a positive deviation of cloudiness and it is accompanied by a larger decrease in UV than would have been expected if only the ozone content deviation and radiation amplification factor equal to 1.1 were taken into account. The reverse situation is observed at the end of the observation period; the fractional deviations of UV are positive and equal to $2 \%$, whereas negative deviations of ozone are only $0.4 \%$, but there are considerable negative deviations of cloudiness. 


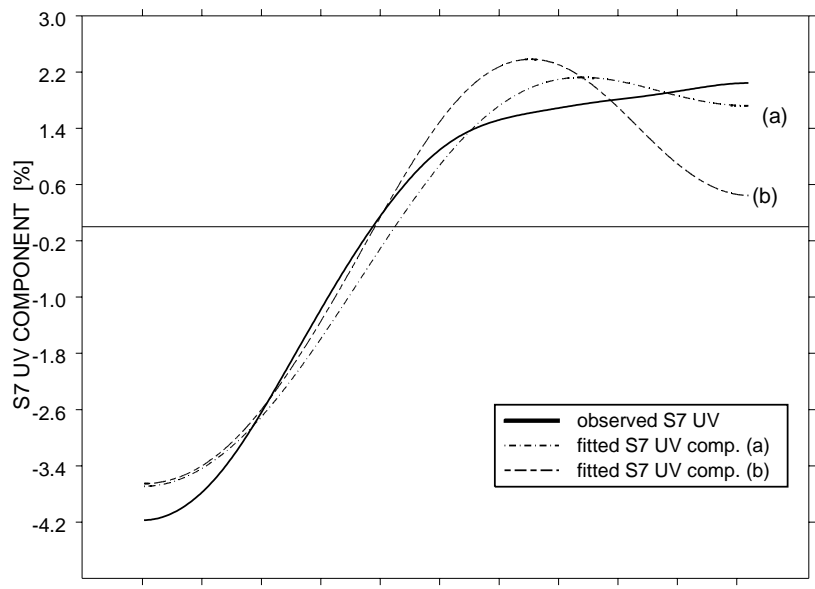

$\begin{array}{lllllllllll}1976 & 1979 & 1982 & 1985 & 1988 & 1991 & 1994 & 1997 & 2000 & 2003 & 2006\end{array}$ YEAR

Fig. 4. Comparison of the observed S7 UV component and fitted with ozone as explanatory variable (a) and with ozone and total cloudiness as explanatory variables (b).

A completely different picture can be seen for the D2 components, which represent variations over a time scale of 2-4 months. In Fig. 3, the D2 component of the UV series is plotted as a function of ozone and cloudiness changes. The negative correlation between UV radiation and ozone content (correlation coefficient is equal to -0.27 ) is not as distinct as for the $\mathrm{S} 7$ components, while a negative correlation between $\mathrm{UV}$ and the clouds is stronger (correlation coefficient is equal to -0.47 ). Wavelet analysis shows that sensitivity of UV radiation to changes in ozone and cloudiness depends on the time scale and the statistical regression model should be adjusted for the particular time scale.

\section{Statistical model and results}

A simple linear regression model was used in the form:

$\mathrm{UV}_{i}^{j}=\beta_{0}^{j}+\sum_{k=1}^{6} \beta_{k}^{j} X_{i, k}^{j}+\varepsilon_{i}^{j}$

where $\mathrm{UV}_{i}^{j}$ is a $j$-th component of the multi-resolution decomposition of the UV series for the $i$-th month, $\beta_{0}^{j}$ is the intercept, $\beta_{1}^{j} \ldots . . \beta_{6}^{j}$ are the regression parameters, $X_{i, 1}^{j} \ldots . . X_{i, 6}^{j}$ are the components of the multi-resolution decomposition of the explanatory variables and $\varepsilon_{i}^{j}$ is the random error term. As explanatory variables the appropriate multi-resolution components of the total cloudiness, low, middle, high clouds cover, ozone and global radiation were used. All components S7, D7... D1, of the UV series were modeled and their sum gave the modeled fractional deviations of UV. Figure 4 shows a comparison of the modeled and observed S7 components of the UV series. If ozone, global radiation and

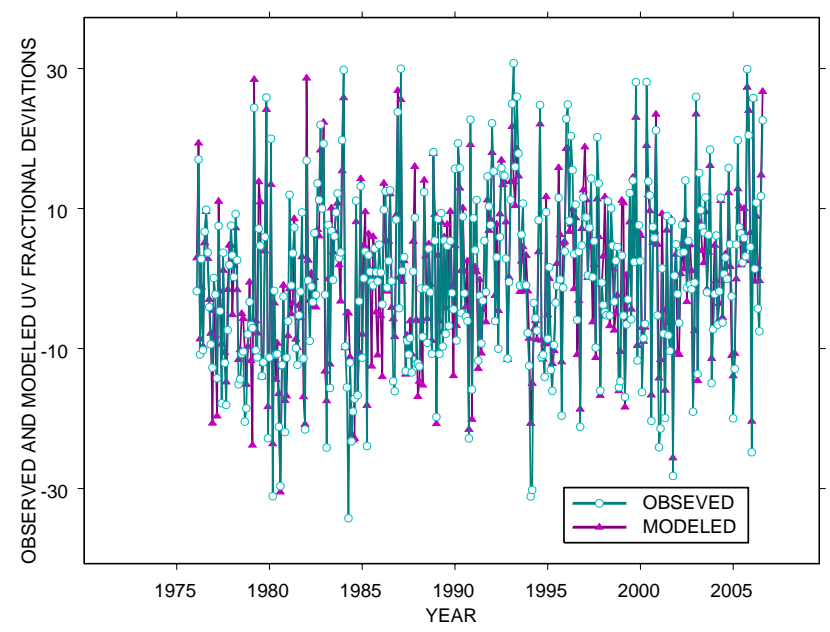

Fig. 5. Comparison of the observed UV fractional deviations and modeled by the method described in the text.

all types of cloudiness are used as explanatory variables, then the modeled UV is a perfect reconstruction of the observed S7 UV component. A good agreement was also obtained if ozone only (curve a) or ozone and total cloudiness (curve b) were used as explanatory variables. It is worth noting that a smooth component of the time series can be used for trend determination (Borkowski, 2002), because the slope of the linear fit of the smooth component is very close to the linear trend determined on the basis of the original series of the fractional deviations. In our case the trend determined from the original series of UV fractional deviations is equal to $2.3 \%$ per decade, while the slope of the linear fit of the S7 UV component also equals to $2.3 \%$ per decade, if S7 UV is modeled with a complete set of explanatory variables, and the same slope is obtained when ozone and total cloudiness are taken as predictors. Thus, the described method can be used for the reliable UV trend estimation for the sites with only an ozone and cloudiness record.

The comparison of the observed and modeled UV series is shown in Fig. 5. The agreement is better than the agreement between the observed series and that modeled by the regression method without decomposition. The residual standard error in the case when total UV deviations are modeled is equal to 6.21, while in the case of a separate modeling of the components at different time scales it is equal to 5.34; thus, it is reduced by $14 \%$.

\section{Conclusions}

Assessment of the UV radiation variability and trend is of considerable interest because of the environmental and health risks caused by an increase in this radiation, whereas the UV measurements network is sparse and the UV data series are short. As a consequence reconstruction methods should be 
used. In this study a statistical regression model was applied to establish a relation between UV radiation and ozone content, global radiation and cloudiness; however, the regression was applied to the individual components of the measured series separately. The wavelet multi-resolution decomposition was used to separate the components at different time scales. The justification of this approach is a different response of UV to the predictors at different time scales. The proposed approach reduces the residual standard error by $14 \%$ with respect to the standard approach. In addition, a slope of the linear fit to the smooth S7 UV component is a reliable estimation of the trend in UV series.

Acknowledgements. This research was partly supported by State Inspectorate for Environment Protection under contract no74/2003/F, and by Ministry of Science and Higher Education under grant 2 POD 06728. I would like to thank anonymous reviewers whose remarks and suggestions improved the paper.

Topical Editor F. D'Andrea thanks three anonymous referees for their help in evaluating this paper.

\section{References}

Bais, A. F., Lubin, D. (lead authors), Arola, A., Bernhard, G., Blumthaler, M., Chubarova, N., Erlick, C., Gies, H. P., Krotkov, N., Lantz, K., Mayer, B., McKenzie, R. L., Piacentini, R. D., Seckmeyer, G., Slusser, J. R., and Zerefos, C. S.: Surface Ultraviolet Radiation: Past, Present, and Future, Chapter 7 in Scientific Assessment of Ozone Depletion: 2006, World Meteorological Organization Global Ozone Research and Monitoring Project - Report No. 50, 572 pp., World Meterological Organization, Geneva, Switzerland, 2007.

Borkowski, J. L.: Homogenisation of the Belsk UV-B series (19761997) and trend analysis, J. Geophys. Res., 105, 4873-4878, 2000.

Borkowski, J. L.: Variations of the UV-B radiation, ozone, and cloudiness at different time scales; a wavelet analysis, Acta Geophys. Pol., 50, 109-117, 2002.

Bruce, A. and Gao, H.-Y.: Applied wavelet analysis with S-PLUS, Springer-Verlag, New York, 338 p., 1996.

Calbó, J., Pagès, D., and González, J.: Empirical studies of cloud effects on UV radiation: A review, Rev.Geophys., 43, RG2002, doi:10.1029/2004RG-000155, 2005.

CIE (International Commission on Illumination): A reference action spectrum for ultraviolet induced erythema in human skin, CIE Research Note, CIE J., 6, 17-22, 1987.

den Outer, P. N., Slaper, H., and Tax, R. B.: UV radiation in the Netherlands: Assessing long-term variability and trends in relation to ozone and clouds, J. Geophys. Res., 110(D2), D02203, doi:10.1029/2004JD004824, 2005.

di Sarra, A., Cacciani, M., Chamard, P., Cornwall, C., DeLuisi, J. J., Di Iorio, T., Disterhoft, P., Fiocco, G., Fuá, D., and Monteleone, F.: Effects of desert dust and ozone on the ultraviolet irradiance at the Mediterranean island of Lampedusa during PAUR II, J. Geophys. Res., 107(D18), 8135, doi:10.1029/2000JD000139, 2002.

Koepke, P., Bais, A. F., Balis, D., Buchwitz, M., De Backer, H., Cabo, X. D., Eckert, P., Eriksen, P., Gillotay, D., Heikkilae, A., Koskela, T., Lapeta, B., Litynska, Z., Lorente, J., Mayer, B., Re- naud, A., Ruggaber, A., Schauberger, G., Seckmeyer, G., Seifert, P., Schmalwieser, A., Schwander, H., Vanicek, K., and Weber, M.: Comparison of models used for UV index calculations, Photochem. Photobiol., 67(6), 657-662, 1998.

Koepke, P., De Backer, H., Bais, A., Curylo, A., Eerme, K., Feister, U., Johnsen, B., Junk, J., Kazantzidis, A., Krzyscin, J., Lindfors, A., Olseth, J. A., den Outer, P., Pribullova, A., Schmalwieser, A. W., Slaper, H., Staiger, H., Verdebout, J., Vuilleumier, L., and Weihs, P.: Modelling solar UV radiation in the past: comparison of algorithms and input data, Proc. SPIE Vol. 6362, 636215, 11 October 2006.

Komhyr, W. D.: Operations Handbook-Ozone Observations with a Dobson Spectrophotometer, WMO Global Ozone Research and Monitoring Project, Report No. 6, 1980.

Krzyscin, J. W.: Nonlinear (MARS) modeling of long-term variations of surface UV-B radiation as revealed from the analysis of Belsk, Poland data for the period 1976-2000, Ann. Geophys., 21, 1887-1896, 2003, http://www.ann-geophys.net/21/1887/2003/.

Krzyscin, J. W., Eerme, K., and Janouch, M.: Long-Term Variations of the UV-B Radiation Over Central Europe as Derived from the Reconstructed UV Time-Series, Ann. Geophys., 22, 1473-1485, 2004, http://www.ann-geophys.net/22/1473/2004/.

Krzyscin, J. W., Jaroslawski, J., and Rajewska-Więch, B.: Beginning of the ozone recovery over Europe? - Analysis of the total ozone data from the ground-based observations, 1964-2004, Ann. Geophys., 23, 1685-1695, 2005, http://www.ann-geophys.net/23/1685/2005/.

Lindfors, A. V., Arola, A., Kaurola, J., Taalas, P., and Svenøe, T.: Long-term erythemal UV doses at Sodankylä estimated using total ozone, sunshine duration, and snow depth, J. Geophys. Res., 108(D16), 4518, doi:10.1029/2002JD003325, 2003.

Lindfors, A. and Vuilleumier, L.: Erythemal UV at Davos, (Switzerland), 1926-2003, estimated using total ozone, sunshine duration, and snow depth, J. Geophys. Res., 110, D02104, doi:10.1029/2004JD005231, 2005.

Madronich, S., McKenzie, R. L., Bjorn, L. O., and Caldwell, M. M.: Changes in biologically active ultraviolet radiation reaching the Earth's surface, J. Photochem. Photobiol. B: Biology, 46, 5-19, 1998.

Madronich, S.: TUV software package version 4.1a, available via anonymous ftp: ftp://sasha.acd.ucar.edu, 1993.

Rajewska-Wiech, B., Bialek, M., and Krzyscin, J. W.: Quality control of Belsk's Dobson spectrophotometer: comparison with the European sub-standard Dobson spectrophotometer and satelite (OMI) overpasses, Publs. Inst. Geophys. Pol. Acad. Sci., D67(382), 115-121, 2006.

Seckmeyer, G., Bais, A., Bernhard, G., Blumthaler, M., Booth, C. R., Lantz, K., and McKenzie, R. L.: Instruments to measure solar ultraviolet irradiance. Part 2: Broadband instruments measuring erythemally weighted solar irradiance, World Meteorological Organization Technical Document No. 1289 (WMO-GAV report 164). 51 p., 2005.

Slaper, H., Velders, G. J. M., Daniel, J. S., de Gruijl, F. R., and van der Leun, J. C.: Estimates of ozone depletion and skin cancer incidence to examine the Vienna Convention achievements, Nature, 384, 256, 1996.

van Weele, M., Martin, T. J., Blumthaler, M., Brogniez, C., den 
Outer, P. N., Engelsen, O., Lenoble, J., Mayer, B., Pfister, G., Ruggaber, A., Walravens, B., Weihs, P., Gardiner, B. G., Gillotay, D., Haferl, D., Kylling, A., Seckmeyer, G., and Wauben, W. M. F.: From model intercomparison toward benchmark UV spectra for six real atmospheric cases, J. Geophys. Res., 105(D4), 49154925, 2000.

Whitcher, B.: waveslim: Basic wavelet routines for one-, twoand three-dimensional signal processing. R package version 1.4., http://www.image.ucar.edu/staff/whitcher/software/, 2004.
World Meteorological Organization (WMO): WMO-UMAP workshop on broad-band UV radiometers, GAW Rep. Ser. 120, 79 pp., 1996.

World Meteorological Organization (WMO): Report of the International Trends Panel, 1988, chap. 4, WMO Rep. 18, Global Ozone. Res. and Monit. Project, Geneva, 1990. 